University for Business and Technology in Kosovo

UBT Knowledge Center

UBT International Conference

2014 UBT International Conference

Nov 7th, 3:45 PM - 4:00 PM

\title{
Seismic analysis of structural building with reinforced concrete shear walls according to the European Standards
}

\author{
Armend Mujaj \\ Polytechnic University of Tirana, armend20mujaj@gmail.com \\ Florim Grajçevci \\ Polytechnic University of Tirana, florim.grajcevci@uni-pr.edu \\ Driton R. Kryeziu \\ Polytechnic University of Tirana, driton_kryeziu@yahoo.com
}

Follow this and additional works at: https://knowledgecenter.ubt-uni.net/conference

Part of the Architecture Commons

\author{
Recommended Citation \\ Mujaj, Armend; Grajçevci, Florim; and Kryeziu, Driton R., "Seismic analysis of structural building with \\ reinforced concrete shear walls according to the European Standards" (2014). UBT International \\ Conference. 4. \\ https://knowledgecenter.ubt-uni.net/conference/2014/all-events/4
}

This Event is brought to you for free and open access by the Publication and Journals at UBT Knowledge Center. It has been accepted for inclusion in UBT International Conference by an authorized administrator of UBT Knowledge Center. For more information, please contact knowledge.center@ubt-uni.net. 


\title{
Seismic analysis of structural building with reinforced concrete shear walls according to the European Standards
}

\author{
Armend Mujaj ${ }^{1}$, Florim Grajçevci ${ }^{2}$, Driton R. Kryeziu ${ }^{3}$ \\ ${ }^{13}$ Politechnical University", Faculty of Civil Engineering in Tirana, \\ ${ }^{2}$ Univeristy of Prishtina, "Faculty of Civil Engineering and Architecture", \\ armend20mujaj@gmail.com¹, florim.grajcevci@uni-pr.edu², driton_kryeziu@yahoo.com³
}

\begin{abstract}
A big research effort has been made on the prediction of earthquakes in the last decades, and in fact the exploration of the new techniques aiming to foresee the occurrence of seismic events is in a continuous progress. Several analytical tools have been developed around the world in order to estimate, with different degrees of accuracy, the vulnerability of buildings and the probable loss of lives and economic resources, due to the occurrence of an earthquake. Those tools are intended to be used by government agencies, and even by insurance companies, as a mean for planning of emergency preparedness procedures and response strategies, and also for the reconstruction phases. Nonetheless, most of the current available tools require a large amount of resources, in terms of money, time and computational effort, in order to be properly implemented and effectively used. The paper presents the basic requirements and procedures for the seismic design of Reinforced Concrete Structure of buildings with non-connected shear walls according to the European Code for Seismic Design of Buildings, Eurocode 8. For the many cases, lifelong and Sustainability of the Structure are depends from the earthquake action, type of structure, quality of materials, height, shape of building etc. Based on devastating effects data from the earthquake strike in recently time for the all around and South East European Countries the Structural type has a prime role for the building capability. Type of structure with structural members shear walls are most sustainable for the resistance of horizontal forces coming from earthquake strikes. The treatment of those structural members such are the shear wall their shape, methodology of reinforced have been give a good performances in capacity of Structure. In the height story buildings the usability of shear walls are very preferable because in one side they are decrease the horizontal deformation.
\end{abstract}

Keywords: Shear wall, Structure, Vulnerability, European Standards

\section{Introduction}

Elements which are normally vertical and support other elements are classified as walls. The vertical walls as structural members are preferable to be used on the case of buildings with more than 10 stories. As a consequence of horizontal actions from the wind and seismic which provoke a considerable lateral displacements, the vertical walls are structural elements with high stiffness to avoid the horizontal displacement of building. Structural scheme of the vertical walls is used to be as cantilever (Inverted pendulum system) with high $\mathrm{H}$ and $1_{\mathrm{w}}$ base length of wall. The ration between of high and length $1_{\mathrm{w}}$ of wall show as follow: ration $\mathrm{H} / \mathrm{l}_{\mathrm{w}}>2$ the wall is bended, when $\mathrm{H} / \mathrm{l}_{\mathrm{w}}<2$ have a shear wall. These types of the structure are grouped as structure with low ductility, for that reason the vertical design action has to satisfy the criteria $v_{d}=N_{E d} / A_{c} f_{c d} \leq 0,40$. In Figure 1. Is graphical show of vertical and base shape of the walls? 

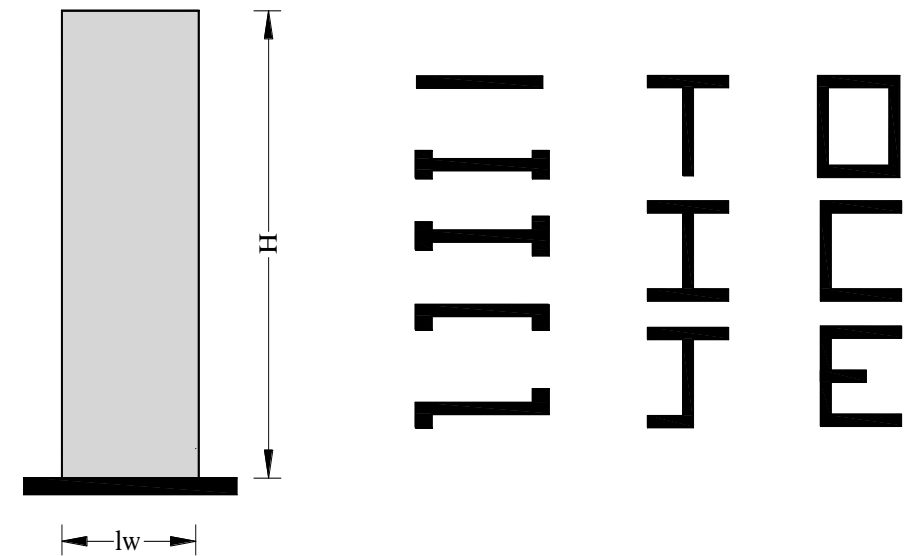

Fig. 1. Graphical shape of vertical element and the shape of cross section of wall

The action effects due to seismic actions are defined in the force-based design method by taking into account that the structural system is in a position to dissipate seismic energy. Therefore, seismic actions are reduced by a factor $q$, which was called there the behavior factor. This factor " $q$ " is related to the ductility demand of the structure as follow:

where

$$
q=q_{0} \cdot k_{w} \geq 1.50
$$

$q_{0} \quad$ is the basic value of the behavior factor, depended on the type of the structural system, related with its redundancy, it is ability to dissipate energy, the number of regions where energy can be dissipated, given in table 1 .

$k_{w} \quad$ is the factor reflecting the prevailing failure mode in structural system with walls given in table 2 .

$\square_{\mathrm{u}} / \square_{1}$ is the factor of ratio related to the overloading, given in table 3 .

Table 1. Basic value of $q_{0}$ of behavior factor for system regular in elevation

\begin{tabular}{|c|c|c|}
\hline STRUCTURAL TYPE & DCH & DCM \\
\hline Frame system, dual system, coupled wall system & 4.5 圆 $_{\mathrm{u}}$ /回 & 3.0 回 $\mathrm{u} /$ ? $_{1}$ \\
\hline Wall system & 4.0 回 $_{\mathrm{u}} / \mathrm{Q}_{1}$ & 3.0 \\
\hline Core system & 3.0 & 2.0 \\
\hline Inverted pendulum system & 2.0 & 1.5 \\
\hline
\end{tabular}

Table 2. Value of $k_{w}$ factor in function of structural type

\begin{tabular}{cc}
\hline STRUCTURAL TYPE & Value of $k_{w}$ \\
\hline Frame system, dual system, coupled wall system & 1.0 \\
Wall system & $0.5 \leq \boldsymbol{k}_{\boldsymbol{w}}=(1+$ ? 0 / [?] [?]?] \\
\hline
\end{tabular}

Where $\square_{0}$ is the prevailing aspect ratio of the walls of the structural system. The prevailing aspect ratio $\square$ o may be determinate as follow:

$$
\square 0=\square H_{w i} / \square l_{w}
$$

Table 3. Value of $\square \mathrm{u} / \square_{1}$ factor of overloading in function of structural type

\begin{tabular}{cc}
\hline STRUCTURAL TYPE & Value of $?_{\mathrm{u}} /$ ? $_{1}$ \\
\hline $\begin{array}{c}\text { Frames or frame-equivalent dual systems: } \\
\text { One-storey buildings }\end{array}$ & $\overbrace{\mathrm{u}} /$ ? $_{1}=1.1$ \\
Multistory, one-bay frames & ? $_{\mathrm{u}} /$ ? $_{1}=1.2$ \\
\hline
\end{tabular}




\begin{tabular}{|c|c|}
\hline $\begin{array}{l}\text { Multistory, multiply frames or frame-equivalent } \\
\text { dual structures }\end{array}$ & 国 ${ }_{\mathrm{u}} / \mathrm{Q}_{1}=1.2$ \\
\hline \multicolumn{2}{|l|}{ Wall- or wall-equivalent dual systems } \\
\hline $\begin{array}{c}\text { Wall systems with only two uncoupled walls per } \\
\text { horizontal direction }\end{array}$ & [? $\left.]_{u} /\right]_{1}=1.0$ \\
\hline Other uncoupled wall systems & ]$_{4} / \Theta_{1}=1.1$ \\
\hline Wall-equivalent dual, or coupled wall systems & 国 $\left.{ }_{1} /\right]_{1}=1.2$ \\
\hline
\end{tabular}

\section{Estimation of the fundamental period $T$}

The fundamental period of vibration required for the simplified design of reinforced concrete structures has been calculated for many years using a simplified formula relating the period to the height of the building. Very rear is going to be used just the first mode of the vibration, excluding the participation of higher mode of vibration. This concept can be use for the buildings with fundamental periods of vibration where approach the top of spectrum, precisely for the structural cases with short and medium self period time of vibration. According to the Eurocode 8, for the buildings with heights up to $40 \mathrm{~m}$ the value of $\mathrm{T}_{1}$ may be approximated by the following expression:

$$
T_{l}=C_{t} \cdot H^{3 / 4}
$$

where $C t$ was a regression coefficient and $\mathrm{H}$ represented the height of the building.

$C_{t}=0.085$ for moment resistant space steel frames

$C_{t}=0.075$ for moment resistant space concrete frames and for eccentrically braced steel frames.

$C_{t}=0.050$ for all other structures

$H \quad$ height of the building, in $\mathrm{m}$, from the foundation or from the top of a rigid basement.

For the alternative, the structure with concrete or masonry shear walls the value $C_{t}$ in expression (3) may taken as follow:

$$
C_{t}=\frac{0.075}{\sqrt{A_{c}}}
$$

where:

$$
A_{c}=\sum\left[A_{i} \cdot\left(0.2+\left(l_{w i} / H\right)\right)^{2}\right]
$$

\section{Distribution of the horizontal seismic forces}

During the wall analysis which is more flexibility its need to take in consideration the post-elastic over strengthening and their uncertainty in the contribution of higher mode shape. Inelastic analysis has show that value of the shear forces are biggest than value came from the linear analysis response. The fundamental mode in the horizontal directions of analysis of the building may be calculated using method of structural dynamics or may be approximated by horizontal displacements increasing linearly along the height of the building. Higher mode effects on inelastic shears are larger in the upper storyes of the wall, and indeed more so in dual structural system. Shear forces should be redistributed along with the bending moments, so that the shear ratio in the individual walls is not appreciably affected. The design bending moment diagram along the height of the wall should be given by an envelope of the bending moment diagram from the analysis, vertically displaced (tension shift). The envelope may be assumed linear, if the structure does not exhibit important discontinuities of mass, stiffness or resistance over its height (see Fig. 2.a). The tension shift should be consistent with the strut inclination considered in the ULS verification for shear, with a possible fan-type pattern of struts near the base, with floors acting as ties. In dual systems containing slender walls the design envelope of shear forces according to Fig. 2.a should be used, to account for uncertainties in higher mode effects. 

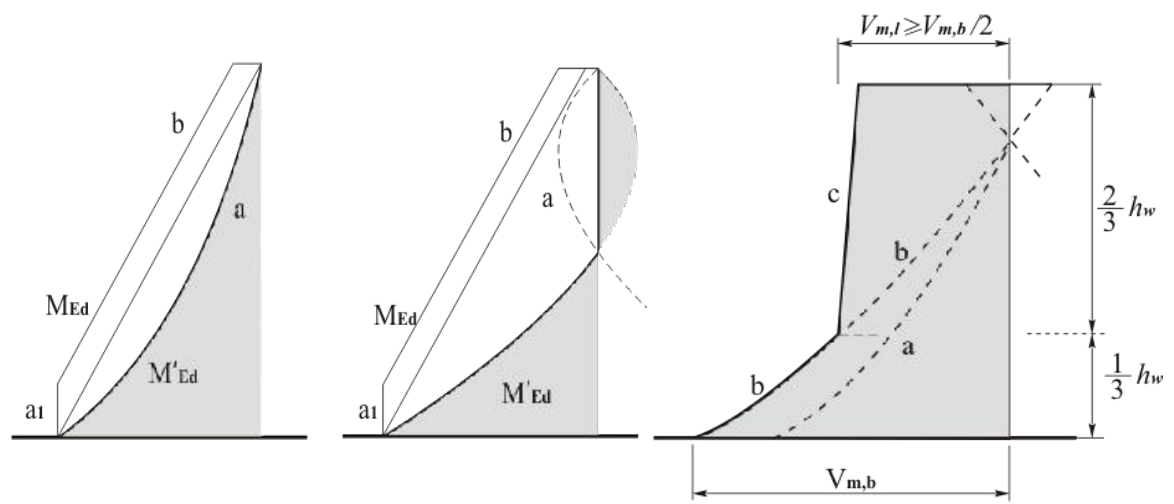

Figure 2. Design envelope for bending moments in slender walls (left side on structural system with wall, right side dual structural system). Legend: a: shear diagram from analysis; $b$ : magnified shear diagram; c: design envelope.

This design diagram, created according to the capacity roles based in EC-8, has to be in consideration to increase the shear force of wall from the appearance of yield in base of wall, Figure 3, design shear force $V_{E d}$. The design shear forces $V_{E d}$ should be derivate according to the expression (6).
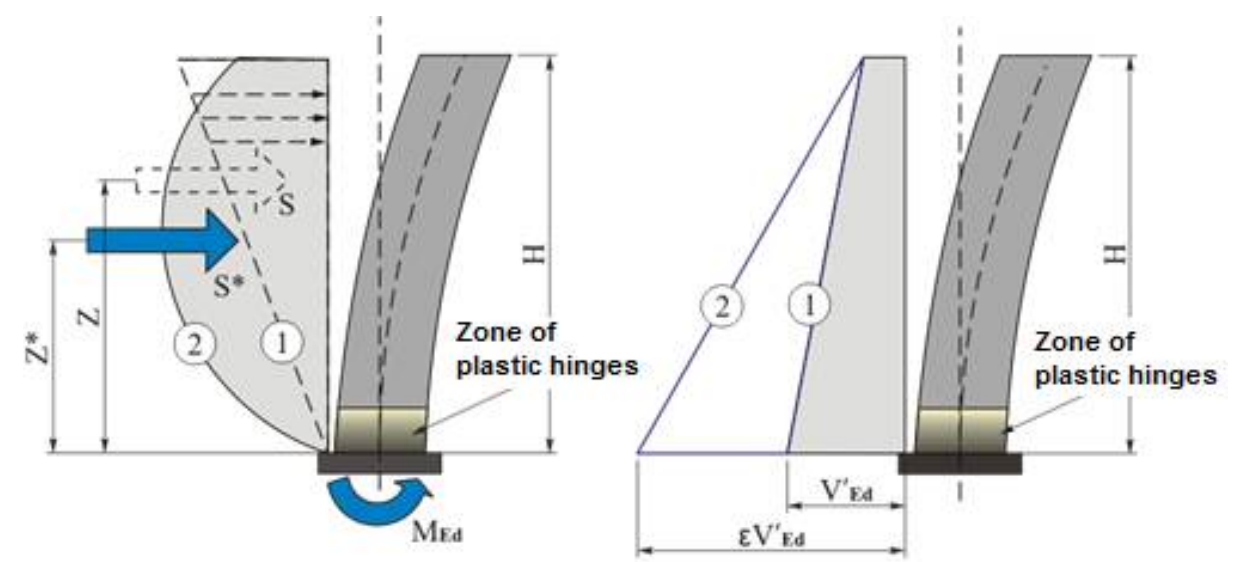

Figure 3. Design shear force from the analysis, $V_{E d}$.

$$
V_{E d}=\varepsilon \cdot V_{E d}^{\prime}
$$

where:

$V_{E d}^{\prime} \quad$ shear design force from the analysis

magnification factor in function of ductility less than 1.5. For the heigh and medium ductility class "DCH and DCM", the factor $\square$ calculated from expression:

$$
\varepsilon=\mathrm{q} \cdot \sqrt{\left(\frac{\gamma_{R d}}{q} \cdot \frac{M_{R d}}{M_{S d}}\right)^{2}+\frac{1}{10} \cdot\left(\frac{S_{e} \cdot\left(T_{c}\right)}{S_{e} \cdot\left(T_{1}\right)}\right)^{2}}<q
$$

for the lower ductility class "DCL", magnification factor is $\square=1.30$.

were:

$q \quad$ behavior factor used in the design

$M_{E d} \quad$ design bending moment at the base of the wall,

$M_{R d} \quad$ design flexural resistance at the base of the wall,

$\square_{R d} \quad$ over strength ration of steel, in the absence of more precise data, $\square R d$ may be taken equal to 1.2

$T_{1} \quad$ fundamental period of vibration of the building in the direction of shear forces $V_{E d}$ 
$T_{C} \quad$ upper limit period of the constant spectral acceleration region of the spectrum, $S_{e}(T) \quad$ ordinate of the elastic response spectrum

In primary walls with a height to length ratio, $h w / l w \leq 2,0$, there is no need to modify the bending moments from the analysis. Shear magnification due to dynamic effects may also be neglected.

The shear force $V_{S d}^{\prime}$ from the analysis should be increased as follows:

$$
\mathrm{V}_{\mathrm{Ed}}=\gamma_{R d} \cdot\left(\frac{M_{R d}}{M_{S d}}\right) \cdot V_{E d}^{\prime} \leq q \cdot V_{E d}^{\prime}
$$

The shear resistance computations and verifications are carried out according to EC-2, unless specified otherwise in the following. In the critical regions of primary seismic beams, the strut inclination $\theta$ in the truss model shall be taken equal to $45^{\circ}$. With regard to the arrangement of shear reinforcement within the critical region at an end of a primary seismic beam where the beam frames into a column, the following cases should be distinguished. Taking into consideration the internal cross section distance forces $x=d_{e}$ equal to $0.8 \cdot 1_{\mathrm{w}}$ with participation of axial forces in tension or pressure is given as follow:

$$
\mathrm{V}_{\mathrm{Ed}} \leq V_{R d 2}
$$

were:

$$
\mathrm{V}_{\mathrm{Ed} 2}=0.5 \cdot\left(0.7-\frac{f_{c k}}{200}\right) \cdot f_{c d} \cdot b_{w} \cdot d_{e}
$$

In the crtical zone is taking the $80 \%$ of value from the uncritical zone, as in expression:

$$
\mathrm{V}_{\mathrm{Ed} 2}=0.4 \cdot\left(0.7-\frac{f_{c k}}{200}\right) \cdot f_{c d} \cdot b_{w} \cdot d_{e}
$$

$f_{c k} \quad$ is in $\mathrm{N} / \mathrm{mm}^{2}$

$$
\text { the factor }\left(0.7-\frac{f_{c k}}{200}\right) \geq 0.5
$$

Excepted control of diagonal in pressure, should be controlled also the tension diagonal. Computed of the reinforcement for rib should be (for the ULS) taking the algebraic value of ratio $\square_{s}=M_{E d} /\left(V_{E d} l_{w}\right)$. During the ultimate limit state in shear control of the cross section in some of levels (floor) should to use a maximum value of the factor $\square_{s}$.

If $\square_{s} \geq 0.2$, it be used the same value given from EC-2 (EN 1992-1-1) for the structural elements beam and column.

If $\square_{s} \leq 0.2$, should be use as the below roles as follow:

The horizontal bars to calculate according to the EC-2 (EN-1992-1-1), filling condition:

$$
\mathrm{V}_{\mathrm{Ed}} \leq \mathrm{V}_{\mathrm{Rd}, \mathrm{ct}}+0.75 \cdot \rho_{h} \cdot f_{y d, h} \cdot b_{w} \cdot \alpha_{s} \cdot l_{w}
$$

were

$\rho_{h}=A_{h} /\left(b_{w} \cdot s_{h}\right)$ ratio of horizontal bars and reinforcement

$f_{y d, h} \quad$ design yield resistance of horizontal bars of reinforcement,

$V_{R d, c t}$ design value of cross concrete section without participation of horizontal reinforcement, according to the (EN-1992-1-1), $x=M_{E d} / V_{E d}$.

Rib vertical anchored and tightening bars in verticality of walls according to the (EN-1192-1-1) should be filling the condition:

$$
\rho_{h} \cdot f_{y d, h} \cdot b_{w} \cdot z \leq \rho_{h} \cdot f_{y d, h} \cdot b_{w} \cdot z+\operatorname{minN}_{E d}
$$

were:

$\rho_{h}=A_{h} /\left(b_{w} \cdot s_{h}\right)$ ratio of horizontal rib and reinforcement

$f_{y d, h} \quad$ design yield resistance of vertical bars of reinforcement,

$N_{E d} \quad$ is design axial forces, in case of pressure is a positive.

In regions of the member where $V_{\mathrm{Ed}} \leq V_{\mathrm{Rd}, \mathrm{s}}$ no calculated shear reinforcement is necessary.

$V_{E d} \quad$ is the design shear force in the section considered resulting from external loading and prestressing (bonded or unbounded).

$V_{R d, s} \quad$ is computed with expression as follow:

$$
V_{R d, s}=V_{d d}+V_{i d}+V_{f d}
$$

were the members are has a follow expression: 


$$
\begin{gathered}
\mathrm{V}_{\mathrm{dd}}=\min \left\{\begin{array}{c}
1,3 \cdot \sum \mathrm{A}_{\mathrm{sj}} \cdot \sqrt{\mathrm{f}_{\mathrm{cd}} \cdot \mathrm{f}_{\mathrm{yd}}} \\
0,25 \cdot \mathrm{f}_{\mathrm{yd}} \cdot \sum \mathrm{A}_{\mathrm{sj}}
\end{array}\right. \\
\mathrm{V}_{\mathrm{id}}=\sum \mathrm{A}_{\mathrm{si}} \cdot \mathrm{f}_{\mathrm{yd}} \cdot \cos \varphi \\
=\min \left\{\begin{array}{c}
\mu_{\mathrm{f}} \cdot\left[\sum\left(\mathrm{A}_{\mathrm{sj}} \cdot \mathrm{f}_{\mathrm{yd}}+\mathrm{N}_{\mathrm{sd}}\right) \cdot \xi+\mathrm{M}_{\mathrm{Ed}} / \mathrm{z}\right] \\
0,5 \cdot \eta \cdot \mathrm{f}_{\mathrm{cd}} \cdot \xi \cdot 1_{\mathrm{w}} \cdot \mathrm{b}_{\mathrm{w}}
\end{array}\right.
\end{gathered}
$$

were:

$V_{d d} \quad$ design resistance of vertical bars,

$V_{d d} \quad$ design shear resistance of inclined bars,

$V_{d d} \quad$ design resistance in friction.

$\square f \quad$ friction factor ob concrete, given in EC-2,

$z \quad$ internal forces distance,

$\square \quad$ factor of neutral axis,

$\square A_{s j} \quad$ vertical reinforced sum area of rib, or additional reinforced bars regarding to shear resistance.

$\square A_{s i} \quad$ incline reinforced sum area of all rib in two directions. It is recommended to be used the bars with diameter more than $\eta=0,6\left(1-f_{c k}\left(\mathrm{~N} / \mathrm{mm}^{2}\right) / 250\right)$.

Using the incline reinforced bars the bending resistance of walls is increase. Computing the design shear force $\mathrm{V}_{\mathrm{Ed}}$ according to the capacity design principle has two methods:

a. Increase the bending resistance $\square M_{R d}$, which is used for the computing of $\mathrm{V}_{\mathrm{Ed}}$ has expression:

$$
\Delta \mathrm{M}_{\mathrm{Rd}}=\frac{1}{2} \cdot \sum \mathrm{A}_{\mathrm{si}} \cdot \mathrm{f}_{\mathrm{yd}} \cdot \sin \varphi \cdot 1_{\mathrm{i}}
$$

were:

$l_{i} \quad$ space between axial central lines of two groups of incline bars referring to angle $\pm \varphi$ against potential slipping plane measured in the base section.

b. is computed the design shear force $V_{E d}$ without heaving in consideration impact of incline bars. In the below expression $V_{\text {id }}$ is consider as clean shear resistance for the incline bars which has expression as follow:

$$
\mathrm{V}_{\text {id }}=\sum \mathrm{A}_{\mathrm{si}} \cdot \mathrm{f}_{\mathrm{yd}} \cdot\left[\cos \varphi-\frac{0,5 \cdot 1_{\mathrm{i}} \cdot \sin \varphi}{\alpha_{\mathrm{s}} \cdot 1_{\mathrm{w}}}\right]
$$

The thickness $b w$ of the confined parts of the wall section (boundary elements) should not be taken less than $150 \mathrm{~mm}$. Moreover, if the length of the confined part does not exceed the maximum of $2 \mathrm{bw}$ and $0,2 l w, b w$ should not be less than $h s / 15$, with $h s$ denoting the storey height; otherwise $b w$ should not be less than $h s / 10$ (Fig. 4.a):
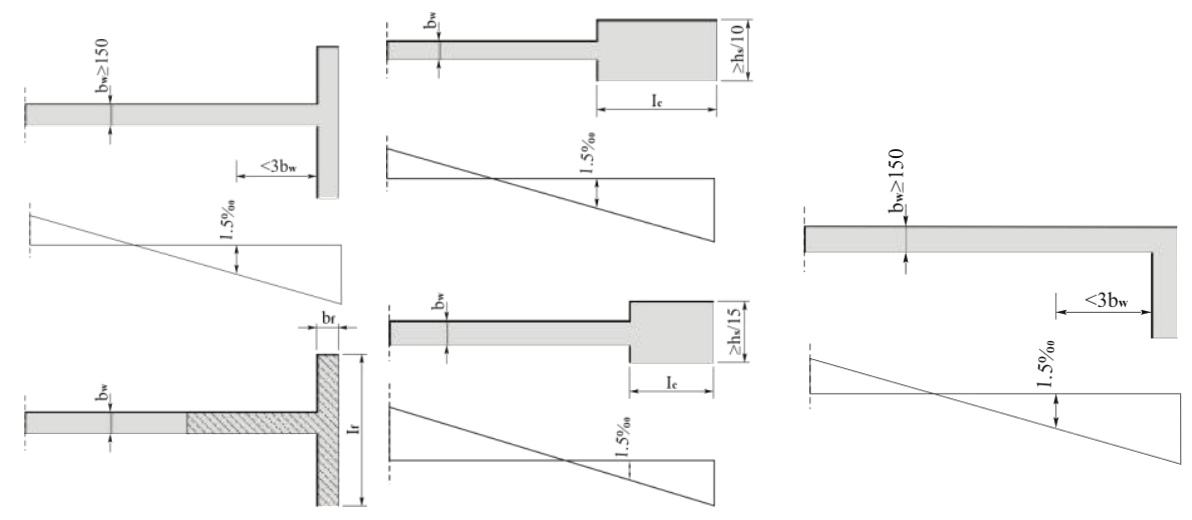
Figure 4. a) Minimum thickness of confined boundary elements; b) for wall ends with large transverse flange

No confined boundary element is required over wall flanges with thickness $h f>h s / 15$ and width $b f>$ $h s / 5$, where $h s$ denotes the clear storey height (Fig. 4.b).

\section{Detailing for local ductility}

the most important of the detailing and special dimensioning rules, through, have a rational basis. these rules and their justification/derivation are given in the following description. The height of the critical region $h_{\mathrm{cr}}$ above the base of the wall may be estimated as:

$$
\mathrm{h}_{\mathrm{cr}}=\max \left\{\frac{\mathrm{1}_{\mathrm{w}}}{\frac{\mathrm{H}_{\mathrm{w}}}{6}}\right.
$$

but

$$
h_{c r}=\max \left\{\begin{array}{c}
2 \cdot l_{w} \\
\left\{\begin{array}{c}
h_{s} \text { for } n \leq 6 \text { storyes } \\
2 \cdot h_{s} \text { for } n \geq 7 \text { storyes }
\end{array}\right.
\end{array}\right.
$$

were:

$l_{w} \quad$ cross section length of the wall

$H w \quad$ total height of the wall from the foundation

$h s \quad$ is the clear storey height and where the base is defined as the level of the foundation or of the embedment in basement storeys with rigid diaphragms and perimeter walls.

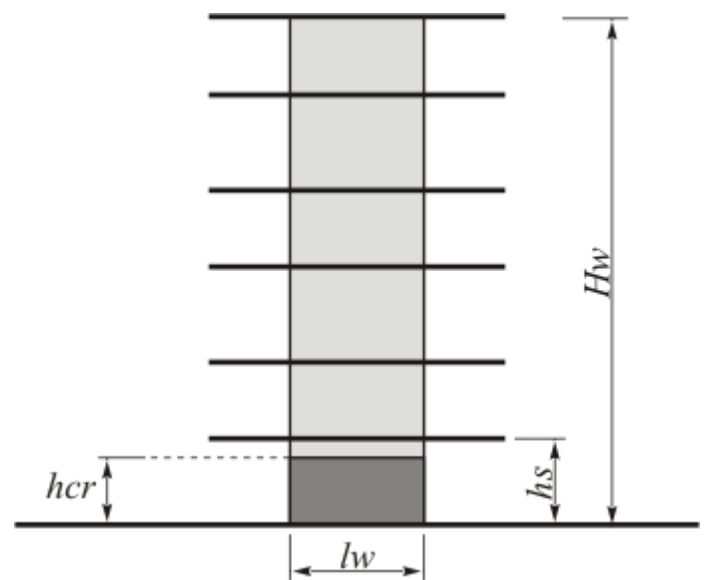

Figure 5. the critical zones in base if the wall.

At the critical regions of walls a value $\square_{\square}$ of the curvature ductility factor should be provided, at least equal to that calculated from expressions (22), (23) as below with the basic value of the behavior factor $q_{\mathrm{o}}$ in these expressions replaced by the product of $q \mathrm{o}$ times the maximum value of the ratio $M_{\mathrm{Ed}} / M_{\mathrm{Rd}}$ at the base of the wall in the seismic design situation $\left(M_{\mathrm{Ed}}=\right.$ design bending moment from the analysis; $M_{\mathrm{Rd}}=$ design flexural resistance)

$$
\begin{gathered}
\mu_{\phi}=2 \cdot q_{0}-1 \text { for } T_{1} \geq T_{c} \\
\mu_{\phi}=1+2 \cdot\left(q_{0}-1\right) \cdot \frac{T_{c}}{T_{1}} \text { for } T_{1}<T_{c}
\end{gathered}
$$

Unless a more precise method is used, the value of $\square \square$ as specified in below may be supplied by means of confining reinforcement within edge regions of the cross-section, termed boundary elements, the extent of which is determined according to given below.

For walls with rectangular section, the mechanical volumetric ratio of the required confining reinforcement $\square_{\text {wd }}$ in boundary elements should satisfy the following equation, with the $\square \square$-values as specified in above: 


$$
\alpha \omega_{\mathrm{wd}} \geq 30 \cdot \mu_{\Phi} \cdot\left(v_{\mathrm{d}}+\omega_{\mathrm{v}}\right) \cdot \varepsilon_{\mathrm{sy}, \mathrm{d}} \cdot \frac{\mathrm{b}_{\mathrm{w}}}{\mathrm{b}_{\mathrm{o}}}-0,035
$$

In the above expressions the numerical values of different magnitudes used in general depends from accepted ductility classes. For the DCH, DCM and DCL have follow values:

$$
\omega_{\mathrm{vd}, \text { min }}=\frac{\mathrm{V}_{\mathrm{h}} \cdot \mathrm{f}_{\mathrm{yd}}}{\mathrm{V}_{\mathrm{o}} \cdot \mathrm{f}_{\mathrm{cd}}}
$$

According to the EC-8, for the factor $\omega_{\mathrm{wd}, \min }$ is given the values as follow:

$$
\begin{aligned}
& \omega_{\text {vd,min }}=\left\{\begin{array}{l}
0,13 \text { për "DCH" } \\
0,08 \text { për "DCM" } \\
0,05 \text { për "DCL" }
\end{array}\right. \\
& \alpha=\alpha_{\mathrm{n}} \cdot \alpha_{\mathrm{s}} \text { and } \alpha_{\mathrm{n}}=1-\sum_{\mathrm{n}} \frac{\mathrm{b}_{\mathrm{i}}^{2}}{6 \cdot \mathrm{A}_{0}}, \alpha_{\mathrm{s}}=\left(1-\frac{\mathrm{s}}{2 \mathrm{~b}_{0}}\right)^{2}
\end{aligned}
$$

For walls with barbells or flanges, or with a section consisting of several rectangular parts (T-, L-, I-, U-shaped sections, etc.) the mechanical volumetric ratio of confining reinforcement in boundary elements may be determined as follows:

a. The axial force and the web vertical reinforcement ratio are normalized to $h_{\mathrm{c}} b_{\mathrm{c}} f_{\mathrm{cd}}$, with the width of the barbell or flange in compression considered as cross sectional width $b_{\mathrm{c}}$

$$
v_{d}=\frac{\mathrm{N}_{\mathrm{Ed}}}{\mathrm{b}_{\mathrm{c}} \cdot \mathrm{h}_{\mathrm{c}} \cdot \mathrm{f}_{\mathrm{cd}}}
$$

The neutral axis depth $x_{\mathrm{u}}$ at ultimate curvature after spalling of the concrete outside the confined core of the boundary elements may be estimated as:

$$
x_{u}=\left(v_{d}+\omega_{v}\right) \cdot \frac{b_{c} \cdot h_{c}}{b_{o}}
$$

in which $b_{\mathrm{o}}$ is the width of the confined core in the barbell or flange. If the value of $x_{\mathrm{u}}$ from expression (29) does not exceed the depth of the barbell or flange after spalling of the cover concrete, then the mechanical volumetric ratio of confining reinforcement in the barbell or flange is determined as in a) above (i.e. from expression (29), with $\square_{\mathrm{d}}, \square_{v}, b_{\mathrm{c}}$ and $b_{\mathrm{o}}$ referring to the width of the barbell or flange.

b. If the value of $x_{\mathrm{u}}$ exceeds the depth of barbell or flange after spalling of the cover concrete, the general method based on:

1) the definition of the curvature ductility factor as $\square \square=\square \mathrm{u} / \square \square \mathrm{y}$,

2 ) the calculation of $\square_{\mathrm{u}}$ as $\square_{\mathrm{cu} 2, \mathrm{c}} / x_{\mathrm{u}}$ and of $\square_{\mathrm{y}}$ as $\square_{\mathrm{sy}} /\left(d-x_{\mathrm{y}}\right)$,

3 ) section equilibrium for the estimation of neutral axis depths $x_{\mathrm{u}}$ and $x_{\mathrm{y}}$, and

4) the strength and ultimate strain of confined concrete, $f_{\mathrm{ck}, \mathrm{c}}$ and $\square$ cu2,c as a function of confining reinforcement $\square_{\text {wd }}$ (see 3.1.9 in EN 1992-1-1:200X) may be followed. The required confining

reinforcement, if needed, and the confined wall lengths should be calculated accordingly.

If more precise data is not available, the compressive strain at which spalling is expected may be taken equal to $\varepsilon_{\mathrm{cu} 2, \mathrm{c}}=0,0035$. The confined boundary element may be considered to extend up to a distance of $\mathrm{x}_{\mathrm{u}}\left(1-\varepsilon_{\mathrm{cu} 2} / \varepsilon_{\mathrm{cu} 2, \mathrm{c}}\right)$ from the hoop centerline near the extreme compression fibre, with the depth of the confined compression zone $x_{\mathrm{u}}$ at ultimate curvature estimated from equilibrium (cf. expression (29) for a constant width $b_{\mathrm{o}}$ of the confined compression zone) and the ultimate strain $\varepsilon_{\mathrm{cu} 2, \mathrm{c}}$ of confined concrete estimated on the basis of 3.1.9 of EN 1992-1-1:200X as $\varepsilon_{\mathrm{cu} 2, \mathrm{c}}=0,0035+0,1 \square \square$ wd $($ Fig. 6). As a minimum, the length $l_{\mathrm{c}}$ of the confined boundary element should not be taken smaller than $0,15<l_{\mathrm{w}}$ or $1,50 . b_{\mathrm{w}}$. 


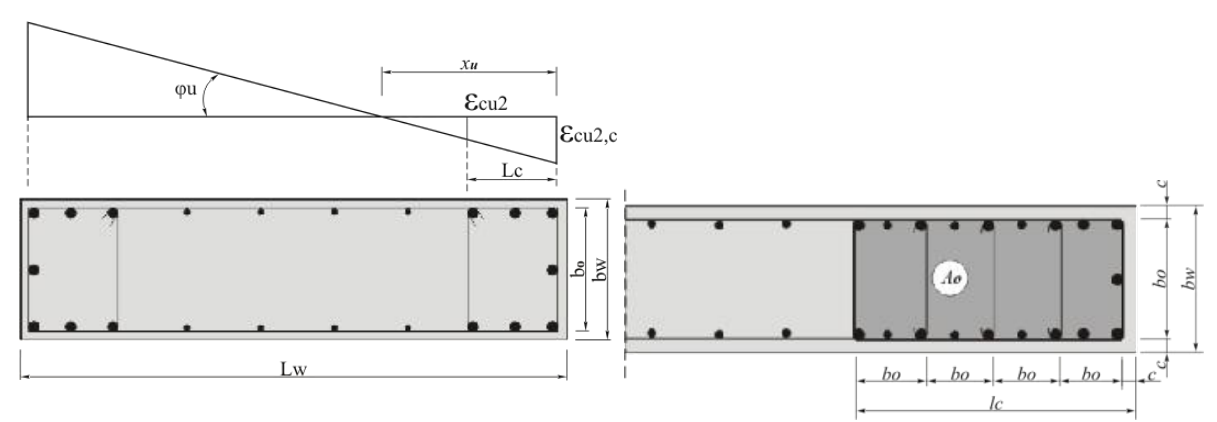

Figure 6. Confined boundary element of free-edge wall end (top: strains at ultimate curvature; bottom: wall cross-section)

Thickness $b_{w}$ of the boundary/flanges section wall should be not les than $20 \mathrm{~cm}$. In addition, if the length of the flanges does not exceed the high value between $2 \cdot b_{w}$ and $0.20 \cdot l_{\mathrm{w}}$ it should be $b_{\mathrm{w}}$ not lower than $\mathrm{h}_{\mathrm{s}} / 15$, see fig. 7 .

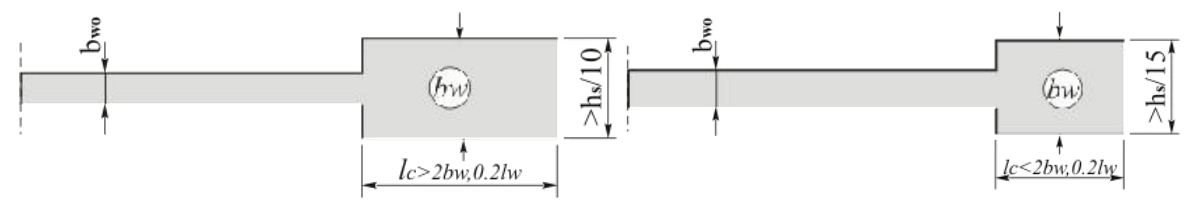

Figure 7. minimum thickness of the boundary strengthening walls element

\section{Numerical part}

To be more precise and convinced in the below are show the study numerical case. The building is reinforced concrete structure vetch Ground +10 floors/levels with story height $h=300 \mathrm{~cm}$ and the regular rectangular shape with dimensions $25 / 20 \mathrm{~m}$. The structure consist with fat slabs which they are supported in beam on perimeter of the floor. This beam has good impact on behavior of the vertical structural elements. In the particular attention it is consider the design of wall M5 from the all required condition from the EC-8, method of reinforced design according to the ductility condition and the control of pressure and tensioned bars. Structural analysis is made in compliance with European standards roles given from EC-0, EC-1, EC-2 and EC-8. Vertical elements columns are neglected from the shear force impacts. Walls are treated as lonely structural elements, they are taking the shear force in plane. From the basement it is possible to se the similar cases on walls M-6, M-9 and M-11.
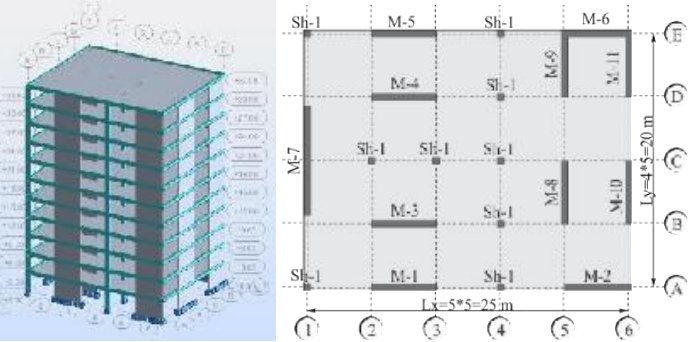

Figure.8. Basement and shape of analyzed structure. 
Table 4. Quality of used for structural material

\begin{tabular}{lll}
\hline Analysis & Statics & Seismics \\
\hline Concrete & $f_{c k}=25 \mathrm{~N} / \mathrm{mm}^{2}$ & $f_{c k}=25 \mathrm{~N} / \mathrm{mm}^{2}$ \\
C-25/30 & $\gamma c=1,50$ & $\gamma c=(1,30-1,50)$ \\
& $f_{c d}=f_{c k} / \gamma_{c}=16.67 \mathrm{~N} / \mathrm{mm}^{2}$ & $f_{c d}=f_{c k} / \nu_{c}=16.67 \mathrm{~N} / \mathrm{mm}^{2}$ \\
Reinforcement & $E=30500 \mathrm{~N} / \mathrm{mm}^{2}$ & $E / 2=15250 \mathrm{~N} / \mathrm{mm}^{2}$ \\
S-500 & $f_{\mathrm{yk}}=500 \mathrm{~N} / \mathrm{mm}^{2}$ & $f_{\mathrm{yk}}=500 \mathrm{~N} / \mathrm{mm}^{2}$ \\
& $\gamma s=1,15$ & $\gamma s=(1,0-1,15)$ \\
& $f_{\mathrm{yd}}=\mathrm{f}_{\mathrm{yk}} / \gamma_{\mathrm{s}}=435 \mathrm{~N} / \mathrm{mm}^{2}$ & $\mathrm{f}_{\mathrm{yd}}=\mathrm{f}_{\mathrm{yk}} / \gamma_{\mathrm{s}}=435 \mathrm{~N} / \mathrm{mm}^{2}$ \\
& $E=20000 \mathrm{~N} / \mathrm{mm}^{2}$ & $E=200000 \mathrm{~N} / \mathrm{mm}^{2}$ \\
\hline
\end{tabular}

In compliance to EN 1998-1,2004 3.2.4(2), EN 1998-1,2004 4.2.4 (2), EN 1990:2012 table A1.1 and EN 1998-1,2004 4.2.4.tabl3 4.2 it is computed the mases on heigh level of building showed in table 5 as follow:

Table 5: calculated of different values for masses, weight, and criteria for structural regularity.

\begin{tabular}{|c|c|c|c|}
\hline Directions & unit & $\mathrm{X}-\mathrm{X}$ & $Y-Y$ \\
\hline masses & [kg] & 584623,30 & 584623,30 \\
\hline weight & {$[\mathrm{kN}]$} & 59594,625 & 59594,625 \\
\hline center of stiffness & [m] & 11,12 & 10,00 \\
\hline center of masses & [m] & 12,50 & 10,00 \\
\hline static eccentricity & [m] & 1,380 & 0,00 \\
\hline accidental eccentricity & [m] & 1,250 & 1,00 \\
\hline dynamic eccentricity & [m] & 0,7025 & 0,00 \\
\hline maximum eccentricity & [m] & 3,3025 & 1,00 \\
\hline minimum eccentricity & [m] & $-0,560$ & $-1,00$ \\
\hline bending & {$[\lambda]$} & 1,25 & 1,25 \\
\hline torsional radius $r_{i}$ & [m] & 15,81 & 13,61 \\
\hline Ls & [m] & 9,242 & 9,242 \\
\hline $0,30 e_{o i}$ & [m] & 4,083 & 4,743 \\
\hline$e_{o i}$ & {$[\mathrm{~m}]$} & 0,00 & 1,38 \\
\hline
\end{tabular}

As it is shown in above table 5, the required criteria from EC-8 regarding to regularity is satisfy, than the structure it is considered as a regular and the methodology for computing it may be used the simply modal analysis method for horizontal seismic forces.

Table 6. Bending polar moment and torsion moment

\begin{tabular}{|c|c|c|c|c|c|c|c|c|c|c|}
\hline Wall & $\begin{array}{c}\mathrm{Ix} \\
\left(\mathrm{m}^{4}\right)\end{array}$ & $\begin{array}{c}\mathrm{Iy} \\
\left(\mathrm{m}^{4}\right)\end{array}$ & $\begin{array}{c}\mathrm{Ixy} \\
\left(\mathrm{m}^{4}\right)\end{array}$ & $\begin{array}{c}\mathrm{x}_{0 \mathrm{i}} \\
(\mathrm{m})\end{array}$ & $\begin{array}{c}\mathrm{y}_{0 \mathrm{i}} \\
(\mathrm{m})\end{array}$ & $\begin{array}{c}\mathrm{Ix} \cdot \mathrm{x}_{\mathrm{0i}} \\
\left(\mathrm{m}^{5}\right)\end{array}$ & $\begin{array}{c}\mathrm{Iy} \cdot \mathrm{y}_{0 \mathrm{i}} \\
\left(\mathrm{m}^{5}\right)\end{array}$ & $\begin{array}{c}\mathrm{Ix} \cdot \mathrm{x}_{\mathrm{i}}{ }^{2} \\
\left(\mathrm{~m}^{6}\right)\end{array}$ & $\begin{array}{c}\mathrm{Iy} \cdot \mathrm{y}_{0 \mathrm{i}}{ }^{2} \\
\left(\mathrm{~m}^{6}\right)\end{array}$ & $\begin{array}{c}\mathrm{I}_{\mathrm{T}} \\
\left(\mathrm{m}^{4}\right)\end{array}$ \\
\hline 1 & 0 & 2.60416 & 0 & 3.62 & 10 & 0 & 26.0416 & 0 & 260.416 & 0.02604 \\
\hline 2 & 0 & 2.60416 & 0 & -11.38 & 10 & 0 & 26.0416 & 0 & 260.416 & 0.02604 \\
\hline 3 & 0 & 2.60416 & 0 & 3.62 & 5 & 0 & 13.0208 & 0 & 65.104 & 0.02604 \\
\hline 4 & 0 & 2.60416 & 0 & 3.62 & -5 & 0 & -13.0208 & 0 & 65.104 & 0.02604 \\
\hline 5 & 0 & 2.60416 & 0 & 3.62 & -10 & 0 & -26.0416 & 0 & 260.416 & 0.02604 \\
\hline 6 & 0 & 2.60416 & 0 & -11.38 & -10 & 0 & -26.0416 & 0 & 260.416 & 0.02604 \\
\hline 7 & 10.667 & 0 & 0 & 11.12 & 0 & 118.61704 & 0 & 1319.0215 & 0 & 0.04167 \\
\hline 8 & 2.60416 & 0 & 0 & -8.88 & 2.5 & -23.12494 & 0 & 205.34947 & 0 & 0.02604 \\
\hline 9 & 2.60416 & 0 & 0 & -8.88 & -7.5 & -23.12494 & 0 & 205.34947 & 0 & 0.02604 \\
\hline 10 & 2.60416 & 0 & 0 & -13.88 & 2.5 & -36.14574 & 0 & 501.70288 & 0 & 0.02604 \\
\hline 11 & 2.60416 & 0 & 0 & -13.88 & -7.5 & -36.14574 & 0 & 501.70288 & 0 & 0.02604 \\
\hline Sum & $\mathbf{2 1 . 0 8 3 6}$ & $\mathbf{1 5 . 6 2 5}$ & & & & & Sum & $\mathbf{2 7 3 3 . 1 2 6 2}$ & $\mathbf{1 1 7 1 . 8 7 2}$ & $\mathbf{0 . 3 0 2 0 7}$ \\
\hline
\end{tabular}


Table 7. Seismic forces and following parameters

\begin{tabular}{llll}
\hline Direction & unit & $\mathbf{X - X}$ & Y-Y \\
\hline building weight & {$[\mathrm{kN}]$} & 59594,625 & 59594,625 \\
base acceleration $\mathrm{a}_{\mathrm{g}}$ & {$\left[\mathrm{m} / \mathrm{s}^{2}\right]$} & $0.25 \mathrm{~g}$ & $0,25 \mathrm{~g}$ \\
fundamental period $\mathrm{T}_{\mathrm{c}}$ & {$[\mathrm{s}]$} & 1.0739 & 1.0271 \\
behavior factor & no & 3.00 & 3.00 \\
spectral type & no & $\mathrm{B}$ & $\mathrm{B}$ \\
spectral ordinate & no & 0.1164 & 0.1217 \\
coefficient $\boldsymbol{\lambda}$ & no & 0.85 & 0.85 \\
factor importance $\boldsymbol{\gamma}_{\mathbf{I}}$ & no & 1.00 & 1.00 \\
base seismic forces & {$[\mathrm{kN}]$} & 5896.30 & 6164.76 \\
\hline
\end{tabular}

Table 8: Distribution of seismic force on the floors of the structure in the direction $\mathrm{x}-\mathrm{x}$

\begin{tabular}{|c|c|c|c|c|c|}
\hline level & $\begin{array}{c}\mathbf{Z i} \\
(\mathbf{m})\end{array}$ & $\begin{array}{c}\mathbf{W i} \\
(\mathbf{k N})\end{array}$ & $\begin{array}{c}\mathbf{W i Z i} \\
(\mathbf{k N m})\end{array}$ & $\begin{array}{c}\mathbf{F b} \\
(\mathbf{k N})\end{array}$ & $\begin{array}{c}\mathbf{F i} \\
(\mathbf{k N})\end{array}$ \\
\hline $\mathbf{1 1}$ & 33 & 4577.13 & 151045.13 & 6164.76 & 879.42 \\
\hline $\mathbf{1 0}$ & 30 & 5501.75 & 165052.50 & 6164.76 & 960.97 \\
\hline $\mathbf{9}$ & 27 & 5501.75 & 148547.25 & 6164.76 & 864.87 \\
\hline $\mathbf{8}$ & 24 & 5501.75 & 132042.00 & 6164.76 & 768.78 \\
\hline $\mathbf{7}$ & 21 & 5501.75 & 115536.75 & 6164.76 & 672.68 \\
\hline $\mathbf{6}$ & 18 & 5501.75 & 99031.50 & 6164.76 & 576.58 \\
\hline $\mathbf{5}$ & 15 & 5501.75 & 82526.25 & 6164.76 & 480.49 \\
\hline $\mathbf{4}$ & 12 & 5501.75 & 66021.00 & 6164.76 & 384.39 \\
\hline $\mathbf{3}$ & 9 & 5501.75 & 49515.75 & 6164.76 & 288.29 \\
\hline $\mathbf{2}$ & 6 & 5501.75 & 33010.50 & 6164.76 & 192.19 \\
\hline $\mathbf{1}$ & 3 & 5501.75 & 16505.25 & 6164.76 & 96.10 \\
\hline & sum & $\mathbf{5 9 5 9 4 . 6 3}$ & $\mathbf{1 0 5 8 8 3 3 . 8 8}$ & & $\mathbf{6 1 6 4 . 7 6}$ \\
\hline
\end{tabular}

Table 9: Distribution of seismic force on the floors of the structure in the direction $y-y$

\begin{tabular}{|c|c|l|l|l|l|}
\hline level & $\mathbf{Z i}(\mathbf{m})$ & $\mathbf{W i}(\mathbf{k N})$ & $\mathbf{W} \mathbf{Z} \mathbf{i}(\mathbf{k N m})$ & $\mathbf{F b}(\mathbf{k N})$ & $\mathbf{F i}(\mathbf{k N})$ \\
\hline $\mathbf{1 1}$ & 33 & 4577.13 & 151045.13 & 5896.30 & 841.12 \\
\hline $\mathbf{1 0}$ & 30 & 5501.75 & 165052.50 & 5896.30 & 919.12 \\
\hline $\mathbf{9}$ & 27 & 5501.75 & 148547.25 & 5896.30 & 827.21 \\
\hline $\mathbf{8}$ & 24 & 5501.75 & 132042.00 & 5896.30 & 735.30 \\
\hline $\mathbf{7}$ & 21 & 5501.75 & 115536.75 & 5896.30 & 643.39 \\
\hline $\mathbf{6}$ & 18 & 5501.75 & 99031.50 & 5896.30 & 551.47 \\
\hline $\mathbf{5}$ & 15 & 5501.75 & 82526.25 & 5896.30 & 459.56 \\
\hline $\mathbf{4}$ & 12 & 5501.75 & 66021.00 & 5896.30 & 367.65 \\
\hline $\mathbf{3}$ & 9 & 5501.75 & 49515.75 & 5896.30 & 275.74 \\
\hline $\mathbf{2}$ & 6 & 5501.75 & 33010.50 & 5896.30 & 183.82 \\
\hline $\mathbf{1}$ & 3 & 5501.75 & 16505.25 & 5896.30 & 91.91 \\
\hline & Sum & 59594.63 & 1058833.88 & & 5896.30 \\
\hline
\end{tabular}

\section{Shear strengthening control}

During the analysis of the structural members and also the completely/assembly of the structure it is important to mentioned that the effect of second theory has direct impact on the chosen methodology for structural analysis, the structure with non moveable joints and moveable joints. it is non that the structural analysis of the elements in this method it is based in deform element. For the request of the structure for non moveable joints, according to the EC-2 need to be satisfy the condition in variety of the floor numbering as follow:

$$
\alpha_{\mathrm{x}}=33 \cdot \sqrt{\frac{69869,25}{47,65625 \cdot 10^{7}}} \leq 0,40<0,6
$$




$$
\begin{aligned}
& \alpha_{y}=33 \cdot \sqrt{\frac{69869,25}{64,3062 \cdot 10^{7}}} \leq 0,344<0,6 \\
& \alpha_{\mathrm{T}}=0,985 \cdot 33 \cdot \sqrt{\frac{69869,25}{3905 \cdot 3,05 \cdot 10^{7}} \cdot\left(\frac{32,02^{2}}{12}+1,38^{2}\right)}=0,233<0,6
\end{aligned}
$$

From the above calculations it is seen that the required condition for "structure with non moveable joints" for the structural analysis it is satisfy, and also the structural stability on torsion.

\section{Verification of the $\boldsymbol{P}$ - $\square$ factor, and limitations of inter story drift}

The P- $\square$ factor is may taken if the below condition satisfy.

$$
\theta=\frac{\mathrm{P}_{\text {tot. }} \cdot \mathrm{d}_{\mathrm{r}}}{\mathrm{V}_{\text {tot. }} \cdot \mathrm{h}_{\text {kat. }}} \leq 0,1
$$

Table 10: structural check from the P- $\square$ factor, direction $X$

\begin{tabular}{|c|c|c|c|c|c|c|c|c|}
\hline level & & $\begin{array}{c}\mathbf{d e r} \\
(\mathbf{m m})\end{array}$ & $\begin{array}{c}\mathbf{d r} \\
(\mathbf{m m})\end{array}$ & $\begin{array}{c}\mathbf{d r} \cdot \mathbf{v} \\
(\mathbf{m m})\end{array}$ & $\begin{array}{c}\text { Ptot. } \\
(\mathbf{k N})\end{array}$ & $\begin{array}{c}\text { Vtot. } \\
(\mathbf{k N})\end{array}$ & $\begin{array}{c}\mathbf{h} \\
(\mathbf{m m})\end{array}$ & $\boldsymbol{\theta}$ \\
\hline $\mathbf{1 1}$ & 86.10 & & & & & & & \\
\hline $\mathbf{1 0}$ & 73.31 & 12.79 & 38.37 & 17.22 & 10078.88 & 1760.24 & 3000.00 & 0.07323 \\
\hline $\mathbf{9}$ & 64.60 & 8.71 & 26.13 & 17.16 & 15580.63 & 2587.46 & 3000.00 & 0.05245 \\
\hline $\mathbf{8}$ & 54.10 & 10.50 & 31.50 & 16.88 & 21082.38 & 3322.75 & 3000.00 & 0.06662 \\
\hline $\mathbf{7}$ & 43.76 & 10.34 & 31.02 & 16.87 & 26584.13 & 3966.14 & 3000.00 & 0.06931 \\
\hline $\mathbf{6}$ & 34.00 & 9.76 & 29.28 & 15.54 & 32085.88 & 4517.61 & 3000.00 & 0.06932 \\
\hline $\mathbf{5}$ & 26.93 & 7.07 & 21.21 & 14.37 & 37587.63 & 4977.18 & 3000.00 & 0.05339 \\
\hline $\mathbf{4}$ & 16.83 & 10.10 & 30.30 & 12.83 & 43089.38 & 5344.83 & 3000.00 & 0.08143 \\
\hline $\mathbf{3}$ & 10.00 & 6.83 & 20.49 & 10.83 & 48591.13 & 5620.56 & 3000.00 & 0.05905 \\
\hline $\mathbf{2}$ & 4.67 & 5.33 & 15.99 & 8.40 & 54092.88 & 5804.39 & 3000.00 & 0.04967 \\
\hline $\mathbf{1}$ & 1.25 & 3.42 & 10.26 & 5.49 & 59594.46 & 5896.30 & 3000.00 & 0.03457 \\
\hline
\end{tabular}

Table 11: structural check from the P- $\square$ factor, direction $Y$

\begin{tabular}{|c|c|c|c|c|c|c|c|c|}
\hline level & $\begin{array}{c}\mathbf{d e} \\
(\mathbf{m m})\end{array}$ & $\begin{array}{c}\mathbf{d e r} \\
(\mathbf{m m})\end{array}$ & $\begin{array}{c}\mathbf{d r} \\
(\mathbf{m m})\end{array}$ & $\begin{array}{c}\mathbf{d r} \cdot \mathbf{v} \\
(\mathbf{m m})\end{array}$ & $\begin{array}{c}\text { Ptot. } \\
(\mathbf{k N})\end{array}$ & $\begin{array}{c}\text { Vtot. } \\
(\mathbf{k N})\end{array}$ & $\begin{array}{c}\mathbf{h} \\
(\mathbf{m m})\end{array}$ & $\boldsymbol{\theta}$ \\
\hline $\mathbf{1 1}$ & 66.76 & & & & & & & \\
\hline $\mathbf{1 0}$ & 58.40 & 8.36 & 25.08 & 13.33 & 10078.88 & 1840.39 & 3000 & 0.046 \\
\hline $\mathbf{9}$ & 50.10 & 8.30 & 24.90 & 13.26 & 15580.63 & 2705.26 & 3000 & 0.048 \\
\hline $\mathbf{8}$ & 41.90 & 8.20 & 24.60 & 13.05 & 21082.38 & 3474.04 & 3000 & 0.050 \\
\hline $\mathbf{7}$ & 33.95 & 8.59 & 25.77 & 12.66 & 26584.13 & 4146.72 & 3000 & 0.055 \\
\hline $\mathbf{6}$ & 25.36 & 8.59 & 25.77 & 12.03 & 32085.88 & 4723.30 & 3000 & 0.058 \\
\hline $\mathbf{5}$ & 19.34 & 6.02 & 18.06 & 11.13 & 37587.63 & 5203.79 & 3000 & 0.043 \\
\hline $\mathbf{4}$ & 13.10 & 6.24 & 18.72 & 9.93 & 43089.38 & 5588.18 & 3000 & 0.048 \\
\hline $\mathbf{3}$ & 7.75 & 5.35 & 16.05 & 8.40 & 48591.13 & 5876.47 & 3000 & 0.044 \\
\hline $\mathbf{2}$ & 3.65 & 4.10 & 12.30 & 6.53 & 54092.88 & 6068.66 & 3000 & 0.037 \\
\hline $\mathbf{1}$ & 0.95 & 2.70 & 8.10 & 4.28 & 59594.46 & 6164.76 & 3000 & 0.026 \\
\hline
\end{tabular}

The inter storey drift may calculated as follow:

$$
\mathrm{d}_{\mathrm{r}} \cdot v \leq 0,0075 \cdot \mathrm{h} \Rightarrow 17,22 \mathrm{~mm}<0,0075 \cdot 3000=22,50 \mathrm{~mm}
$$

From the above calculation it seen that this structure is satisfy the condition for the not heaving into consideration P- $\square$ factor, and also satisfy the interstory drift limitation.

\section{Wall design M5}

The calculation of bending moment, internal shear and axial forces is function of wall stiffness and also the combination of actions in accordance with EN-1998-1, 2004-4.3.3.5.(3). 


\begin{tabular}{|c|c|c|c|c|c|}
\hline \multicolumn{6}{|c|}{$\begin{array}{l}\text { Internal desssign bending moment, internal shear and axial forces for } \\
\text { M5 }\end{array}$} \\
\hline $\begin{array}{l}\text { length } \\
\text { (cm) }\end{array}$ & $\begin{array}{l}\text { thickness } \\
(\mathrm{cm})\end{array}$ & $\begin{array}{l}\mathrm{M}_{\mathrm{sd}} \\
(\mathrm{kN} \cdot \mathrm{m})\end{array}$ & $\begin{array}{l}V_{s d} \\
(k N)\end{array}$ & $\begin{array}{l}N_{\mathrm{sd}} \\
(\mathrm{kN})\end{array}$ & $\begin{array}{l}\mathrm{M}_{\mathrm{sds}} \\
(\mathrm{kN} \cdot \mathrm{m})\end{array}$ \\
\hline 500 & 25 & 22876,30 & 1007,25 & $-3411,25$ & $\begin{array}{l}30551,6 \\
13\end{array}$ \\
\hline
\end{tabular}

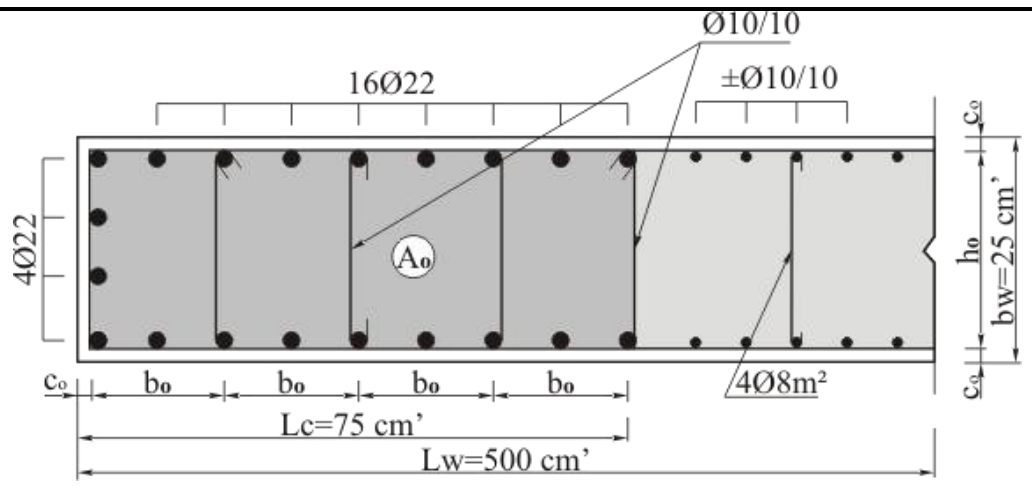

Figure 9: wall design reinforcement of M5

\begin{tabular}{|c|c|c|c|c|c|}
\hline \multicolumn{6}{|c|}{ Design capacity check of wall cross section } \\
\hline $\begin{array}{l}\text { Deformation in } \\
\text { steel and } \\
\text { concrete }\end{array}$ & $\begin{array}{l}\text { Neutral } \\
\text { axis } \\
\text { (m) }\end{array}$ & $\begin{array}{l}\text { design } \\
\text { capacity } \mathrm{N}_{\mathrm{Rd}} \\
(\mathrm{kN})\end{array}$ & $\begin{array}{l}\text { design } \\
\text { capacity } \mathrm{M}_{\mathrm{rd}}{ }^{*} \\
(\mathrm{kNm})\end{array}$ & $\begin{array}{l}\text { design } \\
\text { capacity } \\
\Delta \mathrm{M}_{\mathrm{Rd}}(\mathrm{kN})\end{array}$ & $\begin{array}{l}\text { design } \\
\text { capacity } \mathrm{M}_{\mathrm{rd}} \\
\text { (kN) }\end{array}$ \\
\hline$-3,5 / 10 \%$ & 1,2315 & 3533,57 & 21900,67 & 2556,0 & 24456,67 \\
\hline
\end{tabular}

From the above wall calculation it is seen that the cross section and area of reinforcement are satisfy.

\begin{tabular}{|c|c|}
\hline \multicolumn{2}{|l|}{ Design control from the internal shear forces } \\
\hline Design bending moment $\mathrm{M}_{\mathrm{sd}}(\mathrm{kNm})$ & 22876,30 \\
\hline Design capacity $M_{R d}(k N m)$ & 24456,67 \\
\hline Design Shear force $V_{s d}(k N)$ & 1007,25 \\
\hline Behavior factor (q) & 3,0 \\
\hline Spectral ordinate $S_{d}\left(T_{1}\right)$ & 0,1164 \\
\hline Spectral ordinate $S_{d}\left(T_{c}\right)$ & 0,25 \\
\hline Value of factor $(\varepsilon)$ & 2,41 \\
\hline Design value of shear forces $V_{s^{*}}(k N)$ & 2427,50 \\
\hline Critical value of the zone - wall (m) & 5,50 \\
\hline $\begin{array}{l}\text { Shear design capacity } V_{\mathrm{rd} 2} \text { in critical zone } \\
\text { (kN) }\end{array}$ & 4313,36 \\
\hline $\begin{array}{l}\text { Shear design capacity } V_{r d 2} \text { in noncritical } \\
\text { zone }(k N)\end{array}$ & 5391,70 \\
\hline Value of truss pressure diagonal $V_{\mathrm{Rd} 3}(\mathrm{kN})$ & 3264,68 \\
\hline
\end{tabular}

\begin{tabular}{ll}
\hline Ductility control & \\
\hline $\mathbf{b}_{\mathrm{w}}(\mathrm{cm})$ & 25,0 \\
$\mathbf{I}_{\mathrm{cr}}(\mathrm{cm})$ & 75,0 \\
$\mathbf{b}_{\mathrm{o}}(\mathrm{cm})$ & 20,0 \\
$\mathbf{h}_{\mathrm{o}}(\mathrm{cm})$ & 72,5 \\
$\mathbf{v}_{\mathbf{d}}$ & 0,1637 \\
\hline
\end{tabular}




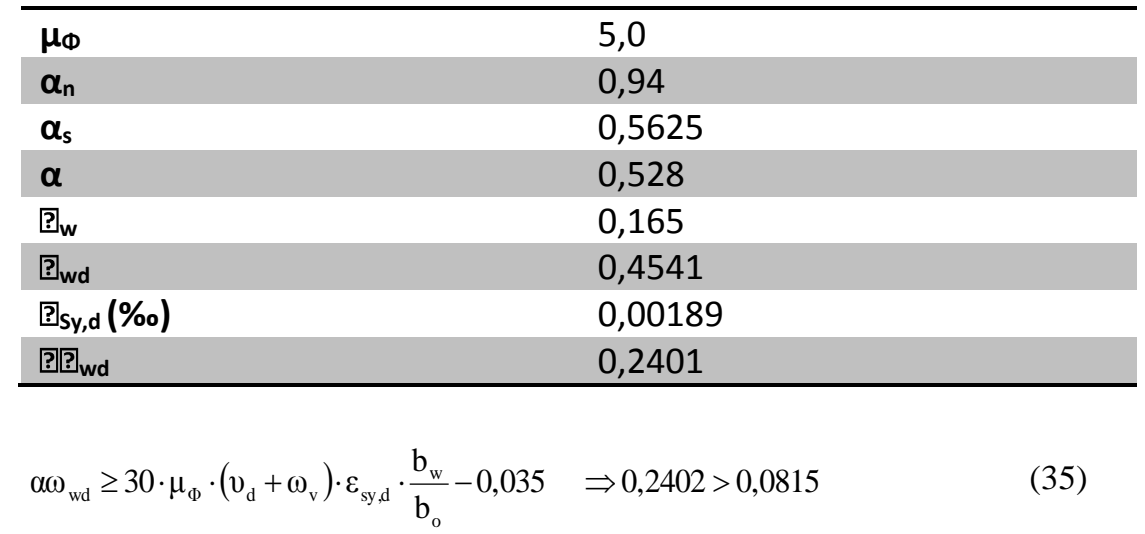

Finally, from the above calculation it is seen that the method of reinforcement design, area of reinforcement for the cross section of the wall satisfy condition for curvature ductility demand against to shear force.

\section{Conclusions}

Traditionally, two requirements must be satisfied to design a structural system with respect to lateral forces: sufficient sectional resistance, and sufficient resistance to lateral displacement.The main target of this paper work is theoretical analysis of structural behavior on the structure with reinforced concrete bearing and shear walls from the seismic horizontal actions. The wall of structural elements, in plane could be treated as a shear wall, bearing capacity and retaining wall in depends from their shape dimensions of cross section, height and the foundation condition. The capital interest of this paper are referring to the civil engineers designers to knowledge general and particular principles for the design of structure with shear walls, their performances, specifics, and also the behavior. Finally, conclusion of this work referring to the structural designers for the seismic zones, in case of reinforced concrete the height story structure with walls is very preferable in the same time is suggestive.

\section{References}

1. Eurocode 8"Design of structures for earthquake resistance-Part 1" General rules seismic action and rules for buildings-Final Draft, Brussels, December 2003

2. GEORGE G. PENELIS and GREGORY G. PENELIS "Concrete Buildings in Seismic Region" 2014

3. MICHAL N. FARDIS " Seismic Design,Assessment and Rretrofitting of Concrete Buildingsbasen on

4. EN-Eurocode 8", Patras Greece 2009

5. Y. ELGHAZOULI, " Seismic Design of Buildings to Eurocode 8", London, 2009

6. ERNEST \& SOHN "Beispiele zur Bemessung nach DIN 1045-1 Band 2- Ingenieurbau", Berlin 2006

7. NIKO POJANI, " Seismic Engineering", Toena,Tirana, 2003 (in Albanian)

8. ARMEND MUJAJ "Behavior of Reinforced Concrete Wall System Under the Seismic Action" Master

9. Thesis Prishtina 2012

10. A.GAULKE \& W.KONN"Konstruktiver Ingenieurbau II Stahlbetonbau”,Berlin 2004

11. JURE RADICं "Betonske Konstrukcije 2", Zagreb 2006 
12. MUSTAFA HRASNICA“ Seizmicka Analiza Zgrada”Sarajevo 2005

13. EMIR HADŹI-MUSIC "Aseizmićke Konstrukcije u Visokogradnji” Sarajevo 1985

14. ALFONS GORIS, WIRTSCHAFTSING, GERHARD RICHTER und HELMUT KIRCHNER"

15. Stalbeton und Spannbeton Nach EC 2 Teil 1 " Berlin 2000

16. Eurocode 0"Basic of structural design",2002

17. Eurocodw 1 "Action on structures"2002

18. Eurocode 2"Design of concrete structures"2004

19. Autodesk Robot Structural Analysis Professional 2015"

20. The design program "AutoCAD 2009". 